\title{
User Engagement and Collaboration in the Next Generation Academic Libraries.
}

\author{
Parisa Saadati \\ University of West London \\ London W5 5RF \\ parisa.saadati@uwl.ac.uk
}

\author{
Elena Pricope \\ University of West London \\ London W5 5RF \\ 21438258@student.uwl.ac.uk
}

\author{
Jose Abdelnour-Nocera \\ University of West London \\ London W5 5RF \\ Jose.Abdelnour-Nocera@uwl.ac.uk
}

\begin{abstract}
The dynamic progress in computing technology is driving the change towards a more centralised and connected society. The technology revolution has transformed cities into smart cities together with all the components. Various studies have shown an interdependence between the quality of life of citizens of smart cities and their level of education. It has been proved that Librarie's access can improve citizens' quality of life and has an essential part in people's education. Traditional libraries improve their services and adapt to the users' expectations using a push strategy, which focuses on predicting user expectations by improving library operations and information system functionality. However, the prediction is not always in line with reality when users are exposed to the most recent technology or forced to change by external forces such as COVID 19 outbreak. Intensive research on smart libraries and how automation can be implemented to support the activities of libraries is available from different backgrounds. The proposed research investigates how the next generation of academic libraries would improve user collaboration using a pull strategy method based on design thinking and a user-centered approach. The proposed research consists of field investigation on users' view in the University of West London library regarding user collaboration and using the survey findings to propose a solution. This paper includes a brief literature review on this topic with findings from previous studies and their limitations and proposed a methodology for collecting and analyzing the data.
\end{abstract}

Future scenarios, automated libraries, post-COVID transformation, user engagement.

\section{INTRODUCTION}

In the current global movement towards urbanisation, cities are now transforming into Smart Cities (SC). The term "smart" usually identified with the level of automation implemented in public and private sectors of a city and how well is Information Technology (IT) integrated into its activities. The main characteristics of SC are smart economy, smart living, smart governance, smart people, smart environment, and smart mobility (Ghosh and Mahesh, 2015). Available SC human aspects research shows a correlation between the education of citizens and the quality of life, and the overall quality of the city. (Ortiz-Fournier et al., 2010; Neirotti et al., 2014; Schopfel, 2018). Libraries are known to have an important role in education as they offer access to information and the physical space where people can interact and exchange ideas.

Libraries have changed over time to adapt to the changing needs of their users, such as ease the borrowing process and improve resource management. It is a common practice that library
Information Systems (IS) are built on top of the legacy systems, integrating and upgrading on specific areas according to the requirements. Often, the upgrades are aimed to support the library staff in order to increase productivity and efficiency. This shows an inside-out approach aimed at the internal processes, and the library IS. The pace with which new solutions are emerging and the fact that library users are experiencing exposure to technology in other environments has become challenging to predict users' exact needs without their involvement. Furthermore, due to the lag between the idea generation and implementation, the new functionality is deployed by the time the users' preferences changed. Lack of communication between software developers and the users also influences this process.

The high amount of easily accessible online information reshaped the use of libraries in the past years from mainly providing access to information to providing a collaborative space for innovation by organising: social gatherings, networking events, targeted learning or entrepreneurship workshops (Leorke, Wyatt and McQuire, 2018). This shows an 
increased need in libraries IS to include functionality that allows users to collaborate, interact and communicate.

Covid-19 pandemic had a significant impact on libraries activities, especially on user collaboration and engagement due to the social distancing measures and other restrictions. Many libraries offered more online services or a hybrid approach where possible. As the situation stands, user collaboration in libraries depends on various IT solutions (available off-shelf) independent from the core library IS. This research is to propose a solution that can increase user collaboration in next-generation academic libraries. The following section looks at the current research studies in this area and their limitations.

\section{LITERATURE REVIEW}

The global value of the library automation market is estimated to reach $\$ 2.8$ billion by 2024 (Hexa Research, 2017). Introducing RFID (Radio Frequency Identification Device) technology integration into libraries in various studies shows that it can automate storage, security, inventory, logistics, and delivery. Therefore, the users can use the library with minimal contact with the library staff (Snehalatha, Punjari and Gadgay, 2018). This novel technology uses radiofrequency tags and sensors to map the location of items, for example. In connection with the library system, the tag can have different values, allowing the user to borrow a book. The efficiency rate of RFID technology decreases when the tags and the sensors are located in the compacted areas. As most of the library's layout tends to be crowded and compact, this considers as one of the main limitations. In addition, to adopt RFID, a library must make a substantial investment to purchase all the equipment needed and integrated it into its system (Ozeer, Sungkur and Nagowah, 2019).

Onnasch et al. study investigated the impact of the Degree of Automation (DOA) on human performance. The research shows that when the DOA is high, the staff tend to be out of the loop due to reduced monitoring, over-trusting the software, and degrading skills. As a result, when the system fails, the impact is highly likely to be negative (2014). However, Tatasciore et al. study shows that high levels of DOA improve the operators' performance by reducing the workload and not affecting the level of situation awareness. The impact of DOA on operators (users) depends on how complex the tasks are automated (2020). These studies have been made in different environments; therefore, the findings reflect the applicability of automation in those situations.

In library management, automation can be the solution to many problems. However, implementing an automated system and its relevant impacts is a change for the libraries, which the users (staff and students) must support to succeed. Otherwise, it is most likely that this functionality will never use, and the project fails. Pre-implementation surveys proved a positive impact on user satisfaction as the user has direct input in the decision-making of the academic library improvements (Chow, 2019).

The development of strategies in libraries traditionally was based on push strategy where the focus is on improving the business activities' efficiency and predicting the users' needs from an inout point of view. In recent years, due to the fast development of computing technology and its influence on users, this approach has been slowly replaced by the pull strategy, which has at its base innovative solutions centered towards the user and uses rapid incremental developments (Nelson, 2016). This shift allows the users to be more involved in the library developments, and it shortens the decision-making time, making the library more agile.

Design Thinking (DT) has improved the quality of applications with user-centric focused solutions in recent years. DT gives a systematic approach to the requirements specifications and increases the innovativeness for an existing approach using the end-user perspective. Therefore, the users' needs are not hypothesized, and instead, an on-field study will help determine what the user needs, how technology can help, and what is a more costeffective solution (De and Vijayakumaran, 2019).

\subsection{Users Involvement and Crowdsourcing}

Library users play an essential part in academic libraries. Users' feedback typically improves the library's digital strategy, emphasizes user involvement, and aligns the libraries' operations with the users' expectations. The increased digitalisation in libraries has permitted the user and library to cocreate value, so-called the value in use (e.g., feedback, applying filters). Islam et al. suggest that the service development process in libraries should focus on value co-creation, involving the students and library staff using interviews and surveys (2015). Various studies support the implementation of crowdsourcing in libraries. The term was first introduced in the academic literature in 2006 by Howe (2006). He defined crowdsourcing as the act of assigning a task (performed by an employee) to a group of people as an open call. The practice involves the user in solving problems or contributing towards the development of various functionalities. Crowdsourcing uses the "mine the users" as a resource to add value to the knowledge generated in the digital library, improve the library services by involving the users in the process, and dimmish the timeframe in which goals are reached (Chhatwal and Mahajan, 2015). However, crowdsourcing adoption in academic libraries assumes mutual trust on both sides: the users and the library. 
Trust is an essential factor in the smooth operation of the libraries. From a general perspective, the users' trust in the library staff will be reflected in the number of users, user interaction, and behavior. The trust level between staff members reflects in the daily activities. A high level of trust is associated with a low rate of sanctions, improves cooperation, increases engagement, enhances accountability, and a higher innovation rate (Wojciechowska, 2021). On the other hand, the disadvantages of using crowdsourcing are the complexity of managing a large group, users' lack of responsibility, and the quality of the solution generated by the crowd, which can be of low quality.

Crowdsourcing adoption in academic libraries can be achieved in a more controlled environment by imposing a private community of users. Therefore, users will be accountable more for their contributions and, at the same time, improve user collaboration in the digital space. Furthermore, using a reward system can motivate and engage the crowd.

User collaboration in libraries is not limited to student-to-student collaboration and group activities. It also covers collaboration between the library staff and the students, for example, in a face-to-face session where students can ask questions from staff and receive guidance on approaching a research topic or using most of the resources available.

The Butler and Byrd study on librarians' and students' perception shows that the students' perception of face-to-face research consultations with the academic librarian is rated higher than the self-evaluation of the librarians. Furthermore, the study shows that students' perception of the consultation is influenced more by the librarianstudent interaction than by the accuracy of the provided information. On the other side, the librarians' perception is affected by the provider's pessimism as the librarians tend to underestimate the value of the consultation (2016).

Despite the current research on smart libraries and automation of library processes, there has been limited research on how IT can increase user collaboration in the next generation academic libraries in both digital and physical space.

\section{PROBLEM STATEMENT}

Covid-19 pandemic forces libraries to speed up adopting a hybrid operation model (dual operations on the digital and physical level). Academic libraries have moved into digital space in order to continue offering their services to users. This has affected the collaboration between students and the library staff due to government restrictions and social distancing regulations. In addition, user behaviour is influenced by new technological developments, as they are exposed to a new technology outside the library.
The proposed study is designed to recommend a framework or guideline that will increase user collaboration in the next generation of academic libraries based on survey findings and intensive literature review on current studies.

\subsection{Research Question}

This study intends to ask how next-generation academic libraries can increase user collaboration in their digital and physical space?

\subsubsection{Research sub-questions}

We also asked the three sub-questions below;

- What are the factors influencing user collaboration in academic libraries?

- What can be done to improve user engagement and collaboration in nextgeneration academic libraries?

- What level of automation will be appropriate to benefit user collaboration?

\section{RESEARCH METHODOLOGY}

\subsection{Overall Aim}

The proposed research aims to recommend an IS framework to improve user collaboration in nextgeneration academic libraries (in digital and physical space). We believe that a list of factors will influence the relationship between users and the digital services in the libraries.

\subsubsection{Research Objectives}

- To investigate the UWL library users' perception of user collaboration.

- To analyse and evaluate the results of the questionnaire in order to find out what are the factors influencing the user collaboration.

- To make recommendations based on the findings.

This research will contribute towards the knowledge of academic libraries development using a pull strategy. Therefore, it can influence the academic library decision-makers, improve operational activities, and drive the change towards the next generation academic library. 


\subsection{Research Methodology}

We will collect both secondary and primary data for this research; an extensive literature review to present the structured findings on the current studies on the topic and a survey evaluation on UWL students. In the library context, the student subjects from the university can be viewed as the major target of library services. Most participants in this study have prior experience of somehow automated services in UWL library. UWL library is not a fully automated library but offers some of the services of a smart library, such as a self-service kiosk, automated returns machine, and use of RFID tags.

The structured questionnaire will analyse and evaluate the UWL students' views regarding user collaboration in the library. The questionnaire will be made available online for a better result. Hence participants can choose the most convenient time to complete the survey. In addition, this option will provide flexibility, and lockdown restrictions will not affect the research stage of the proposed project. This research will not collect or use participants' information or data, making the participants identifiable.

In order to appropriately measure the hypothesis, research items will draw and modify from wellvalidated sales. The advantages of using existing scales are that they fulfill the face and content validity, thus providing a theoretical basis for the assessment domain.

Once the empirical data is collected, the statistical analysis will be made using the phyton programming language (Anaconda platform). We aim to find the correlation between user engagement and some of the variables other literature and models (e.g., technology acceptance model) suggested.

The data visualisation elements will be generated using phyton libraries. The data analysis will provide valuable insight into the users' views regarding user engagement and collaboration.

The main risk of this research is the questionnaire response rate. If the response rate is too low, the study can be biased, and the study validity will decrease.

\subsubsection{Project Timeline}

Here we explain the proposed plan for the research in a broad format. We divided the project into three main stages. During the first stage, the focus is on an intensive literature review and building the questionnaire. The 2nd stage focuse on data collection and analysis; after data collection, two weeks were allocated for the analysis. We aim to collect more than 250 responses, and this may delay this stage. The 3rd stage will focus on the data evaluation and report writing.
We are currently towards the end of the first phase and creating our questionnaire. We hope to publish the complete study of smart libraries at a conference with the smart cities theme in September 2021.

\section{CONCLUSION}

Smart cities is not a new phrase for developed countries. The digital landscape development and technology revolution has transformed cities into smart cities and all the components. Libraries have an important impact on educating citizens of smart cities and reliantly impact their quality of life. A small proportion of Current libraries are partly automated and fitted with RFID tags and other smart technologies. Most of such libraries are among academic libraries and benefit from being open to the users without being staffed or less staffed than before. Using technologies enables remote control of library buildings, including automatic doors, lighting, self-service kiosks, and public computers. However, it still has a long journey to become autonomous, and many changes are expected.

The influence of internal and external forces is pushing libraries to become more automated and offer alternative services. For example, many new knowledge sources and e-learning platforms have been introduced to the users, replacing the traditional use of libraries. On the other hand, the COVID19 outbreak inforces many sectors and industries for an earlier implementation of automated systems than their predicted time. Libraries were not an exception for this.

These new trends are making the libraries more vulnerable with lower user engagement. This makes the researchers and librarians to re-think of using methods to design the future services that can increase the users' engagement in the next generation of libraries. We aim to find the list of factors that impact the users' engagement in academic libraries. We hope we can use the result to find the correlation between these factors and the users' engagement and present our finding as a framework to help decision-makers design better systems for the next generation of academic libraries. 


\section{REFERENCES}

Butler, K. and Byrd, J., 2016. Research Consultation Assessment: Perceptions of Students and Librarians. The Journal of Academic Librarianship, 42(1), pp.83-86.

Chhatwal, A. and Mahajan, P., 2015. CROWDSOURCING IN LIBRARIES: AN OPERATIONAL FRAMEWORK. International Journal of Digital Library Services, 5(3), pp.54-58.

Chow, J. (2019). Realising the potential of user surveys for improving academic libraries: The case of St John's College, Cambridge. Journal of Librarianship and Information Science. 51 (3), 689701.

De, S. and Vijayakumaran, V., 2019. A Brief Study on Enhancing Quality of Enterprise Applications using Design Thinking. International Journal of Education and Management Engineering, 9(5), pp.26-38.

Ghosh, P. , Mahesh, T. R. (2015). Smart City: Concept and Challenges. IJAETS. 1 (1), 25-27. Hexa Research. 2017. Library Management Software Market Size, 2014-2024 / Industry Report. [online] Available at:

https://www.hexaresearch.com/researchreport/library-management-software-market [Accessed 23 January 2021].

Howe, J., 2006. The rise of crowdsourcing. Wired $\begin{array}{lll}\text { Magazine, } & 14 & \text { (6). URL }\end{array}$ http://www.wired.com/wired/archive/14.06/crowds.h $\underline{t m l}$. [Accessed 25 January 202]

Islam, A. , Agarwal, N. K., Ikeda, M. (2015). Conceptualizing value co-creation for service innovation in academic libraries. Business Information Review. 32 (1), 42-52.

Leorke, D., Wyatt, D. and McQuire, S., 2018. "More than just a library": Public libraries in the 'smart city'. City, Culture and Society, 15, pp.37-44.

Neirotti, P., De Marco, A., Cagliano, A., Mangano, G. and Scorrano, F., 2014. Current trends in Smart City initiatives: Some stylised facts. Cities, 38, pp.25-36.

Nelson, J., 2016. Becoming a lean library. 1st ed.

London: Elsevier Ltd. , 29-37.

Onnasch, L., Wickens, C. D., Li, H., Manzey, D. (2014). Human Performance Consequences of Stages and Levels of Automation: An Integrated Meta-Analysis. Human Factors. 56 (3), 476-488.
Ortiz-Fournier, L. V., Marquez, E., Flores, F. R., Rivera-Vazquez, J. C. and Colon, P. A. (2010). Integrating educational institutions to produce intellectual capital for sustainability in Caguas, Puerto Rico. Knowledge Management Research \& Practice .8 (1), 203-215.

Ozeer, A., Sungkur, Y., and Nagowah, S.D. (2019). 'Turning a Traditional Library into a Smart Library', Amity University Dubai, UAE, 11-12 December, 2016, pp. 352-357.

Schöpfel, J. (2018). Smart Libraries. Infrastructures. 3 (43), 2-11.

Snehalatha, Veeresh Pujari, Dr. Baswaraj Gadgay. (2018). Smart Library System Using IoT. International Journal for Research in Applied Science \& Engineering Technology. 6 (7), 471-476.

Tatasciore, M., Bowden, V., Visser, T., Michailovs, S. and Loft, S., 2019. The Benefits and Costs of Low and High Degree of Automation. Human Factors: The Journal of the Human Factors and Ergonomics Society, 62(6), pp.874-896.

Wojciechowska, M., 2021. Trust as a factor in building cognitive social capital among library workers and users. Implications for library managers. The Journal of Academic Librarianship, 47(1), p.102300. 